\title{
Hydroxyderivatives of levoglucosenone in reactions of enantioselective reduction of 1,3-diphenylpropan-1-one
}

\author{
(C) Anna N. Davydova, ${ }^{+}$Bulat T. Sharipov, and Farid A. Valeev* \\ Ufa Institute of Chemistry - Subdivision of the Ufa Federal Research Centre \\ of the Russian Academy of Sciences. Prospect Oktyabrya, 71. Ufa, 450054. Russia. \\ Fax:+7 (3472) 3560 66.E-mail: sharipovbt@anrb.ru
}

*Supervising author; ${ }^{+}$Corresponding author Key words: levoglucosenone, alcohols, enantioselective reduction, hydride reagents.

\begin{abstract}
The enantioselective reduction of prochiral ketones is an important method for the preparation of enanti-enriched secondary alcohols, which can serve as starting materials for optically active compounds. Chiral metal hydride reagents, such as lithium aluminum hydride $\left(\mathrm{LiAlH}_{4}\right)$ and sodium borohydride $\left(\mathrm{NaBH}_{4}\right)$, modified with chiral ligands, have been developed to effect enantioselective reduction. However, in most cases, derivatives are used to obtain chiral hydride reagents, which are rare and hardly available. Therefore, the search for more accessible and effective derivatives suitable for the modification of hydride reagents is an urgent task.

Levoglucosenone is an optically pure enone of carbohydrate nature, readily available by pyrolysis of any cellulose-containing materials. Levoglucosenone is considered a promising bioplatform for both laboratory synthesis and industrial use. The prospect of the development of chemistry of levoglucosenone and its derivatives in industry makes it possible to pay attention to these compounds from the point of view of studying their possibilities as chiral inducers or auxiliaries.

In this work, we studied the possibilities of chiral induction in the reduction reactions of 1,3diphenylpropan-1-one with hydride reagents obtained by replacing hydrogens in $\mathrm{LiAlH}_{4}$ and $\mathrm{NaBH}_{4}$ with hydroxy derivatives of levoglucosenone.

The reduction of 1,3-diphenylpropan-1-one with chiral aluminum hydride reagents proceeded with low enantioselectivity, mainly with a predominance of (S)-1,3-diphenylpropan-1-ol. It was found that the enantiomeric purity of the S-stereomer decreases with an increase in the substitution of hydrogen atoms in $\mathrm{LiAlH}_{4}$ by hydroxy derivatives of levoglucosenone.

Reduction of 1,3-diphenylpropan-1-one with reagents obtained by partial neutralization of $\mathrm{NaBH}_{4}$ with hydroxy derivatives of levoglucosenone, on the contrary, predominantly leads to the formation of $(R)-1,3-$ diphenylpropan-1-ol. The addition of $\mathrm{AcOH}$ and $\mathrm{Bu}_{4} \mathrm{NCl}$ to $\mathrm{NaBH}_{4}$ has a positive effect on the optical frequency of the $R$-alcohol. At the same time, enantioselectivity in the reactions was almost absent upon reduction of 1,3-diphenylpropan-1-one with reagents obtained by partial neutralization of $\mathrm{BH}_{3}$.

The best results of enantioselective reduction were shown by unsaturated alcohols: $(1 S, 4 S, 5 R)-6,8$ dioxabicyclo[3.2.1]oct-2-en-4-ol and $(1 S, 4 S, 5 R)$-4-methyl-6,8-dioxabicyclo[3.2.1]oct-2-en-4-ol, of which (1S, 4S,5R)-6,8-dioxabicyclo[3.2.1]oct-2-en-4-ol was the most effective. It is likely that an increase in the enantioselectivity of reactions carried out in the presence of hydroxy derivatives of levoglucosenone is possible by obtaining more bulky chiral ligands, provided that the double bond is retained.
\end{abstract}

\section{References}

[1] S. Itsuno. Enantioselective reduction of ketones. Organic Reactions. 1998. Vol.52. P.395-576.

[2] M.B. Comba, Y.-H. Tsai, A.M. Sarotti, M.I. Mangione, A.G. Suárez, R.A. Spanevello. Levoglucosenone and its new applications: valorization of cellulose residues. Eur. J. Org. Chem. 2018. P.590-604.

[3] A.M. Sarotti, M.M. Zanardi, R.A. Spanevello, A.G. Suárez. Recent applications of levoglucosenone as chiral synthon. Curr. Org. Synth. 2012. Vol.9. P.439-459.

[4] M.S. Miftakhov, F.A. Valeev, I.N. Gaisina. Levoglucosenone: the properties, reactions, and use in fine organic synthesis. Russ. Chem. Rev. 1994. Vol.63. P.869-882.

[5] F. Shafizadeh, R.H. Furneaux, T.T. Stevenson. Some reactions of levoglucosenone. Carbohydr. Res. 1979. Vol.71. P.169-191. 
[6] A.N. Davydova, B.T. Sharipov, F.A. Valeev. Eleuthesides and their analogs: IX. Synthesis of $C^{3}-C^{8}$ eleutheside block from levoglucosenone. Russ. J. Org. Chem. 2015. Vol.51. C.1408-1417.

[7] B.T. Sharipov, A.N. Davydova, L.Kh. Faizullina, F.A. Valeev. Preparation of the diastereomerically pure 2S-hydroxy derivative of dihydrolevoglucosenone (cyrene). Mendeleev Commun. 2019. Vol.29. P.200202.

[8] A.N. Davydova, B.T. Sharipov, and F.A. Valeev. Synthesis of ether derivatives of levoglucosenone and some aspects of their use. Butlerov Communications. 2018. Vol.56. No.10. P.58-63. DOI: 10.37952/ROIjbc-01/18-56-10-58

[9] A.N. Davydova, B.T. Sharipov, A.S. Ryabova, N.F. Galimzyanova, F.A. Valeev. Synthesis and fungicidal activity of methylsulfanylmethyl ether derivatives of levoglucosenone. Chemistry of Heterocyclic Compounds. 2019. Vol.55. No.1. P.31-37. (russian)

[10] T. Sato, Y. Gotoh, Y. Wakabayashi, T. Fujisawa. Asymmetric reduction of $\alpha, \beta$-unsaturated ketones with chiral hydride reagents prepared from lithium aluminum hydride and $(S)$-4-anilino- and $(S)-4-(2,6-$ xylidino)-3-methylamino-1-butanol. Tetrahedron Letters. 1983. Vol.24. P.4123-4126.

[11] Z. Cao, Z. Liu, Y. Liu, H. Du. Pd-Catalyzed asymmetric allylic etherizations with oximes by chiral alkene-phosphine ligands. J. Org. Chem. 2011. Vol.76. P.6401-6406. 